\title{
Bridging the Gap: Building Local Resilience and Competencies in Remote Communities
}

\author{
Mads Gilbert, MD, PhD
}

\author{
Department of Emergency Medicine, \\ University Hospital of North Norway, \\ Tormsoe, Norway \\ Correspondence: \\ E-mail: mads.gilbert@gmail.com
}

Keynote address delivered at the 15th World Congress for Disaster and Emergency Medicine, 16th May 2007, Amsterdam, The Netherlands

Web publication: 27 August 2008
This keynote address will focus on the potential to reduce the increasing gap between rich and poor countries. This critical gap only can be bridged if we systematically replace the expensive and reactive international disaster post-boc operations by systematic, long-term, proactive efforts to increase the local capacity to master everyday accidents and emergencies as well as empower the local preparedness for major events such as natural and technological events. If we really wish to strengthen local preparedness and competencies in remote communities in low- and middle-income countries (LMIC, "the South"), we must systematically share knowledge and skills through scientifically proven training programs aimed at such impoverished, still densely populated regions in the South. Such local training represents a sustainable, long-term action to build emergency medical capacity into the local population and the health workers, as opposed to only relying on expensive foreign relief that arrive too late, is cost ineffective, and most often responds to spectacular disasters. Building local competence also strengthens local resilience (Table 1).

As stated by Dr. Claude de Ville de Goyet, medical assistance should respond to primary healthcare needs in the affected countries rather than to the perceptions of a far away, well-intentioned, but misinformed public. It often remains unclear whether emergency medical assistance is meant to benefit the affected populations in the South, or generate donors to the rapidly growing relief industry, recently named "the largest unregulated industry" by Red Cross in its 2004 Disaster Report. Also, the important remarks made by Dr. Rahardjo regarding the different views and conclusions if disasters-and other emergencies-are seen from the perspective of the local people or from the external parties offering help.

\section{Is "The Chain of Survival" Only for the Rich World?}

Health disparities between countries are not diminishing. On the contrary, the rich North steadily becomes more affluent in income as well as health services and life expectancies. A well-organized "chain of survival" for medical emergencies and accidents is taken for granted in most rich communities in the North. Similar emergency medical systems (EMS) remain practically absent in most of the South, despite extensive research and development of new methods for prehospital and hospital life-saving strategies. Techniques for treating most critical medical problems and complications have been available for more than half of a century.

The sharp backdrop for this merciless, unbalanced development is that a full $80-90 \%$ of the burden of disease related to trauma and cardiovascular diseases occurs in the South precisely where such systematic "chains of survival" are non-existing (except some urban areas). And, despite this, more than $80 \%$ of global expenditure on the same conditions occurs in the high-income countries. Similar inequities also are extremely prominent for maternal and infant mortality rates, and little if any progress has been made during the last 15 years. Women still risk death in order to give life, and simple and affordable changes in antenatal and neonatal care only are slowly being implemented, much too slowly for more than half of the world's women and babies.

Obviously, given similar biological tolerance to hypoxia and hypoperfusion, time-critical emergencies must be given proper immediate life-saving 


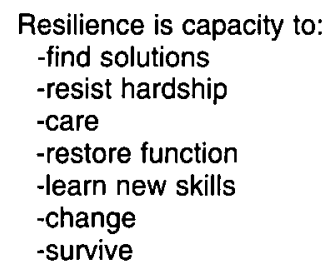

Table 1-Resilience

\begin{tabular}{|l|l|}
\hline \multicolumn{1}{|c|}{ Bam \& Armenia } & \multicolumn{1}{c|}{ California, USA } \\
- Poor & - Rich \\
- Weak infrastructure & - Quake-resistant infrastructure \\
- Buildings & - Buildings \\
- Water & - Water \\
- Roads & - Roads \\
- Health care & - Health care \\
- No early warning system & - Early warning systems \\
& -Geology, meteorology, civil- \\
- No population training & - Wian \\
- South & - North \\
\hline
\end{tabular}

Table 3-System and preparedness differences between North and South accounting for variations in survival after earthquakes

first aid followed by adequately timed definite medical treatment whether they occur in Cambridge or Cambodia. Simple and cost-effective interventions can prevent many premature deaths, however the poor populations at greatest need too often lack access to such help. Belated and costly international relief operations are too slow and mostly inappropriate to substantially reduce avoidable deaths in large accidents and disasters, let alone in everyday accidents and medical emergencies. Basic life support must be athand in the local community if it shall impact mortality and morbidity in such time-critical events as trauma, neardrowning, and cardiovascular diseases.

There are several case studies of earthquakes that shows striking differences in survival chances depending on infrastructure, prevention, and EMS preparedness (Table 2). For example, every hour of delayed extrication and first aid resulted in 20 dead for every 1,000 victims buried or trapped by the earthquake in Armenia in 1988. For every hour the rescue could have been advanced, 800 people could have been saved and BLS response three hours earlier would save 2,400 lives. However, 25,000 died. One of the important, but later not materialized lessons learned from the Armenia earthquake was that effective basic and advanced life support given at the right time, can significantly reduce the morbidity and mortality of trauma victims. In 1989, Peter Safar and co-workers concluded that a significant percentage of the local population should learn six basic steps in order to improve survival:

1. Airway control;

2. Mouth-to-mouth rescue breathing;

3. External bleeding control by compression;

4. Recovery position;

5. Shock position; and

6. Rescue pull.

\begin{tabular}{|l|r|r|c|}
\hline \multicolumn{1}{|c|}{ Place } & Strength & Deaths & Injuries \\
\hline Armenia (1989) & $6.6 \mathrm{Mw}$ & 25,000 & $>35,000$ \\
\hline California (1993) & $6.6 \mathrm{Mw}$ & 61 & 8,000 \\
\hline Bam, Iran (2003) & $6.6 \mathrm{Mw}$ & 30,000 & $>50,000$ \\
\hline
\end{tabular}

Table 2-Typical differences in earthquake survival

These simple and scientific recommendations have not been followed by large-scale training of vulnerable populations in the South. While $15 \%$ of disaster victims live in high-income countries, they constitute only $1.8 \%$ of disaster deaths. Yet, the "Majority World" with the poorest populations faces the majority of disasters and has the weakest early warning systems, least public training programs, and weakest preparedness plans.

This absence of systematic teaching, training, and development in first aid and basic emergency services at the local level in highly vulnerable, high-risk communities costs hundred of thousands of lives every year. The shift in the burden of disease and emergencies from communicable to non-communicable diseases (heart disease, stroke, cancer) and trauma, puts even larger strains on the local emergency medical systems-if they exist at all in remote communities.

To strengthen these communities that represent the majority of the world's populations and the heaviest burden of disease, we must systematically build long-term local capacity and competence. Only then can we expect to save lives and limbs and reduce avoidable deaths in time-critical medical conditions. This is true not only following disasters, but also more importantly, in the everyday medical and surgical emergencies. The everyday emergencies represent the major source of preventable loss of lives and function. Even modest investments in health in general, and emergency medical systems in particular, have been shown to have tremendous effects on the lives of the world's most vulnerable. We currently are facing two major obstacles to progress: (1) inequality in access; and (2) inappropriate international emergency medical actions.

\section{Increasing Global Inequalities}

Despite increasing global wealth, since 1990, the gap between rich and poor has increased, not decreased (Table 3 ). In the recent commitment to free-market economic policies, insufficient account has been taken on the effects on the poor, the vulnerable, and the environment. The result is that the world is more unequal now than 10 years ago:

1. Despite progress in some contexts, health and education inequalities have widened, especially within countries;

2. Sub-Saharan Africa and parts of Asia are in the worst predicament;

3. The UN's "Millennium Goals" are lost in Africa and most of Asia;

4. Poverty has increased or is stagnant in all regions in the South (except parts of Asia);

5. The number of poor people in sub-Saharan Africa has increased by almost 90 million in a little more than a decade (1990-2001); 


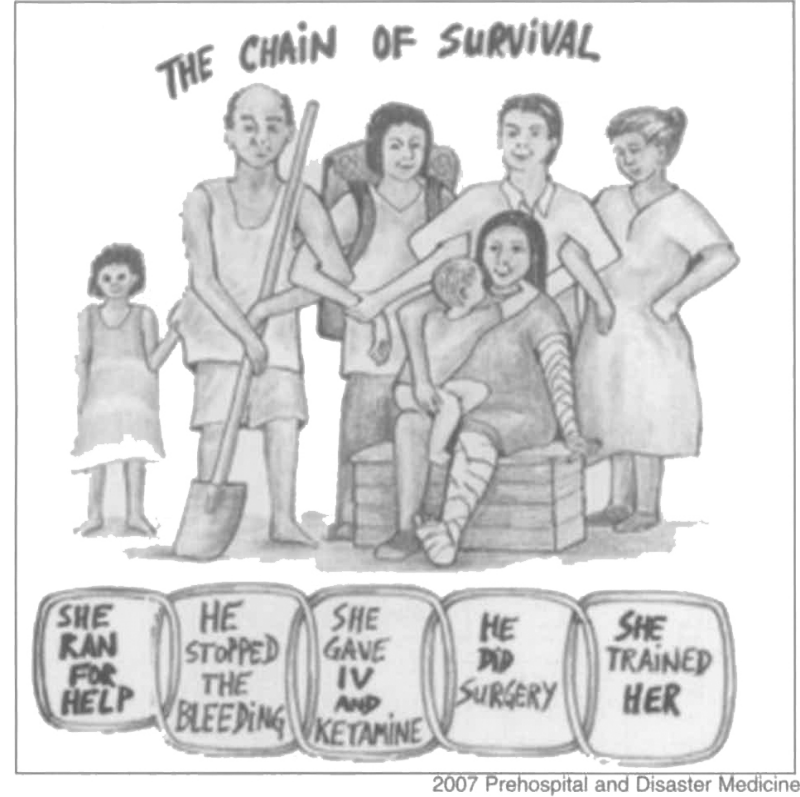

Figure 1-An alternative "chain of survival" for the South

Source: Third World Network

6. Seventy-seven percent of the population subsists on less than two dollars a day, and this percentage has hardly changed over 20 years (1981-2001);

7. Life expectancy in Africa is 15 years shorter than it was in 1990;

8. The South has $>150$ million underweight children;

9. 30,000 children die daily before the age of five;

10. $80 \%$ of world BNP belongs to the rich $20 \%$;

11. $20 \%$ of world BNP is shared by the 5 billion poor in the South; and

12. Increasing inequalities threaten social and political stability. (UN Report on The World Social Situation 2005: The Inequality Predicament. DESA, 2005).

"The global public goods" such as comprehensive medical knowledge among local health workers and basic training of lay people is even more unequally distributed. This not only is highly prominent in prevention and medical care for common diseases, but even more in the field of emergency and disaster medicine.

The unbalanced global distribution of health workers adds to the emergency medical crisis. While the World Health Organization (WHO) norm is minimum 100 nurses and 20 doctors per 100,000 populations, the rich countries have several hundred to $>1,000$ nurses and 200-400 doctors per 100,000. Samples of eight African countries shows 8.8 to 113.1 nurses and 3.4 to 13.2 doctors per 100,000 . Such critical lack of local health workers is prominent particularly in rural areas in the South.

Unless attention is paid to redressing global inequality and pursuing the comprehensive vision of social development agreed upon at the Social Summit in Copenhagen in 1995, the UN report on The World Social Situation 2005 warns that the inequality predicament will be perpetuated, frustrating efforts to achieve the Millennium Development
Goals. Health is the most important foreign policy issue of our time, according to a recent editorial comment in The Lancet.

\section{"The Village University"}

Resilience means capacity to withstand hardship. Systematically building local "chains of survival" through local, sustainable training methods will strengthen lay peoples' mastering and control and reduce avoidable deaths locally.

Injury and trauma is a major cause of premature death and disability worldwide. The "epidemic of trauma" is glob$\mathrm{al}$, and $90 \%$ of the fatalities are found in low- and middleincome countries. Studies of trauma system effectiveness in western, high-income societies indicate a $15-20 \%$ improved survival rate in seriously injured patients after trauma.

The pattern of mortality differs in less developed countries with prehospital transit times for trauma victims of 4 to 8 hours not being uncommon, with trauma mortality rates as high as 40 to $50 \%$ with mostly prehospital fatalities. The majority of trauma victims who die suffer hypoxia from obstructed airways, hypotension from uncontrolled bleeding augmented by accidental hypothermia, and later infections (septicemia). For example, a high proportion of children injured by landmines die from bleeding without reaching hospitals. The misuse of tourniquets in traumatic extremity bleeding adds to the risk of uncontrolled bleeding. Training simple techniques for BLS theoretically should improve survival.

We have developed simple, systematic training programs targeting rural populations in low-income countries with a high incidence of high-energy trauma (in particular landmines). The program is feasible, affordable, and saves valuable time. Systematic capacity building easily can be done with simplified local "chains of survival" for trauma victims in regions with no doctors, public emergency phone systems, dispatch centers-let alone modern ambulances (Figure 1). Prehospital trauma mortality can be dramatically reduced.

In rural, mine-infested communities in Cambodia and Kurdistan, we have shown that such systematic training of local health workers and villagers in basic and advanced life support for trauma victims significantly reduced prehospital mortality from $30 \%$ to $8-9 \%$ over a 3-8 year period. The reason for this substantial mortality reduction was simply that training locals in basic and advanced trauma resuscitation skills significantly reduced the time from accident to stabilization of vital functions. Fairly simple maneuvers for airway control, control of hemorrhage, and hypothermia prevention had substantial effects, while more advanced skills such as chest tube and fasciotomies were rarely needed.

Reduced hypoxia time means less acidosis; less hypothermia means less bleeding - and the replacement of widespread abuse of tourniquets with systematic deep gauze packing and elastic bandages reduced hypoperfusion due to blood loss. Also, we found that simple, non-invasive clinical triage tools can be extracted from such low-cost systems.

Important success factors for this program included the development of local teaching tools such as inexpensive manuals translated to local languages, affordable training tools (improvised manikins for cardiopulmonary resuscitation (CPR)-training, use of live models for practical train- 
ing), and systematic training of local trainers. All training sessions occurred at the village level in target rural regions with long prehospital evacuation times ( 450 hours over three years for medics, 1-2 days for first responders). From 1997-2006, >10,000 first responders and trauma medics have been trained by local instructors treating more than 3,000 mostly trauma patients. The 1,061 trauma cases we studied in Cambodia and Kurdistan treated by local "first responders" and "trauma medics" with basic emergency medical equipment and drugs had quite severe injuries (mean ISS $=12.4$ ) and long prehospital evacuation times to hospital (mean 5.7 hours). A majority (55\%) of 1,061 trauma victims studied with ISS $>9$ received intravenous (IV) ketamine (mean $=38 \mathrm{mg}$ ) for pain control during evacuation, and all patients with blood pressure $>90 \mathrm{mmHg}$ received warmed IV crystalloid solutions.

\section{Conclusions}

"The Village University" training concept results in increased local resilience, more survivors from prehospital trauma and emergencies, and sustainable development of local "chains of survival". The model is affordable and relies heavily on local control and local health workers and villagers, not external or foreign "experts". Such programs significantly improve survival and also can be implemented for medical and obstetrical emergencies. Systematic transfer of knowledge and skills in low-cost training programs probably yield far better results than high-tech, costly, and short-lived disaster missions from North to South. Such pragmatic solidarity projects also increase our understanding of fundamental cultural, economical and political realities behind the increasing gaps between the poor and rich.
Bibliography

Africa Working Group of the Joint Learning Initiative on Human Resources for Health and Development. "The Health Workforce in Africa: Challenges and Prospects." 2006.

de Ville de Goyet, Claude and Emile Jeannee. "Earthquake in Guatemala: Epidemiological Evaluation of the Relief Effort." Emergency Planning Digest $4(1977): 2-8$.

Hill, Kenneth, Kevin Thomas, Carla AbouZahr, Neff Walker, Lale Say, Mie Inoue, and Emi Suzuki: "Estimates of Maternal Mortality Worldwide Between 1990 and 2005: An Assessment of Available Data." The Lancet 370 (2007):1311-1319.

Husum, Hans, Mads Gilbert, and Torben Wisborg. Save Lives Save Limbs! Penang, Malaysia: Third World Network, 2000.

Husum, Hans, Mads Gilbert, and Torben Wisborg. "Training Pre-hospital Trauma Care in Low-Income Countries: The 'Village University' Experience." Medical Teacbing 25 (1998):142-148.

Husum, Hans, Mads Gilbert, Torben Wisborg, Yang Van Heng, and Mudhafar Murad. "Land Mine Injuries: A Study of 708 Victims in North Iraq and Cambodia." Military Medicine 168 (2003):934-940.

Husum, Hans, Mads Gilbert, Torben Wisborg, Yang Van Heng, and Mudhafar Murad. "Rural Prehospital Trauma Systems Improve Trauma Outcome in Low-Income Countries: A Prospective Study from North Iraq and Cambodia." The Journal of Trauma Injury, Infection and Critical Care 54 (2003):1188-1196.

Husum, Hans, Mads Gilbert, Torben Wisborg, Yang Van Heng, and Mudhafar Murad: "Respiratory Rate as a Prehospital Traige Tool in Rural Trauma." The Journal of Trauma Injury, Infection and Critical Care 55 (2003):466-470.

Husum, Hans, Mads Gilbert, Torben Wisborg, and Johan Pillgram-Larsen: "Ban the Tourniquet!" The Journal of Trauma Injury, Infection and Critical Care 56 (2004):214-215.
Husum, Hans, Tone Olsen, Mudhafar Murad, Yang Van Heng, Torben Wisborg, and Mads Gilbert: "Preventing Post-Injury Hypothermia During Prolonged Prehospital Evacuation." Prehospital and Disaster Medicine 17 (2002):23-26.

Klain, Miroslav, Edmund M. Ricci, Peter Safar, Victor Semenov, Ernesto A. Pretto, Samuel A. Tisherman, and Joel Abrahams: "Disaster Reanimatology Potentials: A Structural Interview Study in Armenia: I. Methodology and Preliminary Results." Prehospital and Disaster Medicine 4 (1989):135-184.

Krug, Etienne G. "Injury: A Leading Cause of the Global Burden of Disease." (WHO/HSG/PVI/99.11). Geneva, Switzerland: World Health Organization, 1999.

Mock, Charles: "Improving Prehospital Trauma Care in Rural Areas of Low-Income Countries." The Journal of Trauma Injury, Infection and Critical Care 54 (2003): 1197-1198.

People's Health Movement, Global Health Watch, Medact, Global Equity Gauge Alliance, and University of South Africa. Global Health Watch 20052006: An Alternative World Health Report. London, United Kingdom: Zed Books, 2005.

Pretto, Ernesto A., Edmund M. Ricci, Miroslav Klain, Peter Safar, Victor Semenov, Samuel A. Tisherman, David Crippen, Louise K. Comfort, and Joel Abrams: "Disater reanimatology potentials: A structured interview study in Armenia: III. Results, Conclusions, and Recommendations." Prehospital and Disaster Medicine 7 (1992):135-184.

Sasser, Scott, Mathew Varghese, Arthur Kellermann, and Jean-Dominique Lormand. "Prehospital Trauma Care Systems." Geneva, Switzerland: World Health Organization, 2005.

The United Nations Children's Fund (UNICEF), State of the Worlds Children, 1995.

The United Nations, Department of Economic and Social Affairs, Report on the World Social Situation 2005: The Inequality Predicament, Report on the World Social Situation 2005: The Inequality Predicament, 2005, A/60/117/Rev.1 ST/ESA/299, New York USA.

World Health Organization, Global Burden of Disease Project, 2001, Version 1.

Zupan, Jelka: "Perinatal Mortality in Developing Countries." New England Journal of Medicine 352 (2005):2047-2048. 